\title{
A comparative study of feto-maternal outcome in instrumental vaginal delivery at tertiary health level hospital in Uttarakhand state
}

\author{
Priyanka Chaudhari*, Neeta Bansal, Vineeta Gupta, Archna Tandon, Anjali Chaudhry
}

Department of Obstetrics and Gynaecology, Shri Guru Ram Rai Institute of Medical and Health Sciences, Dehradun, Uttarakhand, India

Received: 29 August 2016

Accepted: 03 September 2016

\section{*Correspondence:}

Dr. Priyanka Chaudhari,

E-mail: dishitapriya07@gmail.com

Copyright: (C) the author(s), publisher and licensee Medip Academy. This is an open-access article distributed under the terms of the Creative Commons Attribution Non-Commercial License, which permits unrestricted non-commercial use, distribution, and reproduction in any medium, provided the original work is properly cited.

\begin{abstract}
Background: Instrumental vaginal delivery is an age-long obstetric practice used to expedite vaginal delivery or avert recourse to caesarean delivery. Objective of the study is to compare maternal and neonatal outcomes of vacuum and forceps application in instrumental vaginal delivery.

Methods: This is a retrospective observational study. Retrospective study of 70 consecutive ventouse and 70 consecutive forceps deliveries was done. Maternal and neonatal morbidity were compared in terms of perineal laceration, episiotomy extension, postpartum hemorrhage, apgar score, neonatal injuries and NICU admissions.

Results: Maternal morbidity in terms of periurethral tear, second and third degree perineal tear were significantly more in forceps group ( $\mathrm{p}=0.0332$ and $\mathrm{p}=0.0173$ respectively). However neonatal outcomes were found to be similar in both types of instrumental deliveries.

Conclusions: Ventouse should be preferred over forceps whenever there is an indication for instrumental delivery (except in fetal distress) as it is associated with less maternal trauma and most of the neonatal morbidities were insignificant in comparison with both instruments.
\end{abstract}

Keywords: Instrumental delivery, Forceps, Vacuum extraction, Maternal morbidity, Perinatal outcomes

\section{INTRODUCTION}

Vacuum extraction and forceps are the two options when an instrument is needed to facilitate a vaginal birth. The choice between these two options has usually been based on tradition and training. ${ }^{1}$ In North America, forceps has been used more frequently than vacuum extraction whereas reverse is true in Europe and Asia. ${ }^{2-4}$ Vacuum extraction has recently gained in popularity because of new designs of vacuum cups with reduced risk of injury to the neonate. ${ }^{5}$ James Young Simpson was the first to use traction to deliver a baby in 1849. It was later modified by Malmstrom in 1953.The obstetric forceps had its history from the time of Chamberlain family in the seventh century.
Modern obstetric practice has witnessed an increased caesarean rate worldwide. Assisted vaginal delivery, with the use of forceps and vacuum extraction, offers the option to accomplish safe delivery for the mother and clinician. It avoids caesarean section and its associated morbidity and implications for future pregnancy. Forceps and vacuum have been compared in many studies. ${ }^{6-9}$ Review of the literature suggests different maternal and neonatal outcomes and complications rates between the two methods. Both are associated with increased risk of maternal and neonatal injury when compared to normal spontaneous vaginal deliveries. Poor maternal and neonatal outcome has also been reported after the sequential use of vacuum and forceps for assisted vaginal delivery. ${ }^{10}$ Furthermore, it has been repeatedly shown that maternal injury is less frequent and less extensive with the use of vacuum. 
With this background the present study has been carried out to evaluate the maternal and neonatal morbidity, failiure and complications associated with these two instruments for assisted vaginal deliveries, at tertiary health care centre in the region of Uttarakhand State.

\section{METHODS}

A total of 140 cases of instrumental deliveries were taken in this retrospective study. It is carried out at SGRRIM\&HS hospital, Dehradun, Uttarakhand. Seventy (70) consecutive cases of vacuum assisted delivery and seventy (70) consecutive cases of forceps assisted delivery were scrutinized for demographic data, various indications for instrumental delivery, parity, gestational age, maternal morbidity and neonatal outcomes. Exclusion criteria from both the groups were cases of multiple pregnancy, preterm (<34 wks of gestation) and breech presentation (for forceps in after coming head).Institutional Ethical Committee approval was taken.

The instruments used for vacuum extraction were sialistic $40 \mathrm{~mm}$ and $60 \mathrm{~mm}$ cups. The negative pressure applied was upto $0.6 \mathrm{~kg} / \mathrm{cm}^{2}$. Forceps deliveries were performed using short curved outlet Wrigley's forceps.

Maternal morbidity was analyzed in terms of perineal, vaginal and cervical lacerations, episiotomy extensions, urinary and fecal incontinence and traumatic post partum hemorrhage. Neonatal complications in both groups included low apgar score at birth, unexplained convulsions, jaundice, facial and scalp injuries, cephalhaematoma, birth asphyxia, neonatal sepsis and NICU admissions. They all are compared in both groups. Condition of mother and neonate at the time of discharge was noted. $\chi^{2}$ (Chi Square) test was used to analyze the data and $\mathrm{p}$ value $<0.05$ was considered as statistically significant.

\section{RESULTS}

Instrumental deliveries are an important tool to decrease caesarean rates and associated morbidity, only when strict protocols are followed. United States have the instrumental delivery rates between 10 and $15 \% .{ }^{11}$ In our institution we found instrumental delivery rate between 9 and $15 \%$ in last five years.

The mean age of women in our study was $26 \pm 3.12 \mathrm{yrs}$ in ventouse and $25 \pm 4.45 \mathrm{yrs}$ in forceps group. In our study $58.5 \%$ of ventouse deliveries and $71.4 \%$ forceps deliveries were carried out in primigravida. Mean birth weight in our study was $2.88 \pm 0.41 \mathrm{~kg}$. We observed that birth weight $>3.5 \mathrm{~kg}$ was significantly more common in forceps group $(\mathrm{p}=0.0144)$. Our study also showed that the use of instruments were more frequent in infants with higher birth weight and gestational age. We found no significant difference in apgar scores at 1 \& 5 minutes, between the two study groups.

Table 1: Maternal and Neonatal characteristics.

\begin{tabular}{|c|c|c|c|c|}
\hline Characteristics & & Ventouse $(n=70)$ & Forceps $(n=70)$ & P value \\
\hline Maternal age & Years; (Mean \pm SD) & $26 \pm 3.12$ & $25 \pm 4.45$ & NS \\
\hline \multirow{2}{*}{ Parity n (\%) } & Primiparous & $41(58.5 \%)$ & $50(71.4 \%)$ & NS \\
\hline & Multiparous & $29(41.5 \%)$ & $20(28.6 \%)$ & NS \\
\hline \multirow{3}{*}{$\begin{array}{l}\text { Gestational age } \\
\text { (weeks) }\end{array}$} & $<37$ & $01(1.4 \%)$ & $03(4.3 \%)$ & NS \\
\hline & $37-40$ & $58(82.9 \%)$ & $53(75.7 \%)$ & NS \\
\hline & $>40$ & $11(15.7 \%)$ & $14(20 \%)$ & NS \\
\hline \multirow{6}{*}{ Birth weight (gm) } & $<2.000$ & $03(4.8 \%)$ & $04(6.2 \%)$ & \multirow{6}{*}{$\begin{array}{l}\text { NS } \\
\text { NS } \\
\text { NS } \\
\text { NS } \\
\text { S }(0.0144)\end{array}$} \\
\hline & $2.001-2.500$ & $19(30.7 \%)$ & $13(20 \%)$ & \\
\hline & $2.5001-3.000$ & $27(43.5 \%)$ & $18(27.7 \%)$ & \\
\hline & $3.001-3.5000$ & $10(16.1 \%)$ & $17(26.2 \%)$ & \\
\hline & $3.501-4.000$ & $02(3.2 \%)$ & $09(13.9 \%)$ & \\
\hline & $>4.000$ & $01(1.7 \%)$ & $04(6.2 \%)$ & \\
\hline \multirow{3}{*}{$\begin{array}{l}\text { Apgar score } \\
\text { (at } 1 \mathrm{~min} \text { ) }\end{array}$} & $0-3$ & - & $03(4.6 \%)$ & - \\
\hline & $4-6$ & $13(20.9 \%)$ & $20(30.8 \%)$ & NS \\
\hline & $7-10$ & $49(79.1 \%)$ & $42(64.6 \%)$ & NS \\
\hline \multirow{3}{*}{$\begin{array}{l}\text { Apgar score } \\
\text { (at } 5 \mathrm{~min} \text { ) }\end{array}$} & $0-3$ & - & $02(3.1 \%)$ & NS \\
\hline & $4-6$ & $7(11.3 \%)$ & $12(18.5 \%)$ & NS \\
\hline & $7-10$ & $55(88.7 \%)$ & $51(78.4 \%)$ & NS \\
\hline
\end{tabular}

NS-non significant p-value (>0.05), S-significant p-value $(<0.05)$

Most common indication was to cut short the second stage of delivery $(42.14 \%)$ as in cases of PIH, eclampsia, previous caesarean section, heart disease, severe anemia. Other indications were prolonged second stage of labour which was seen in $25.7 \%$ of ventouse and $12.9 \%$ of forceps deliveries. Poor maternal efforts were found in $4.3 \%$ of forceps and $14.3 \%$ of ventouse delivery. Maternal distress was observed in $4.3 \%$ of ventouse and 
$4.3 \%$ of forceps delivery. we observed that if the indication of instrumental delivery is fetal distress, then forceps is the instrument of choice $(32.9 \%)$ as compared to ventouse $(12.9 \%)$ and this difference is found to be significant $(\mathrm{p}=0.0082)$.The decision to delivery interval was $8.4 \pm 5.1 \mathrm{~min}$ for forceps and $15.4 \pm 6.8 \mathrm{~min}$ in ventouse assisted deliveries. This difference is also significant $(p=0.0001)$. It shows that it is quicker to deliver the baby by forceps than ventouse, which makes forceps as a preferred choice in fetal distress cases.

Table 2: Indications for application.

\begin{tabular}{|c|c|c|c|}
\hline Indications & $\begin{array}{l}\text { Ventouse } \\
(\mathrm{n}=70)\end{array}$ & $\begin{array}{l}\text { forceps } \\
(n=70)\end{array}$ & P value \\
\hline $\begin{array}{l}\text { Prolonged } \\
\text { second stage }\end{array}$ & $18(25.7 \%)$ & $9(12.9 \%)$ & NS \\
\hline $\begin{array}{l}\text { Poor maternal } \\
\text { effort }\end{array}$ & $10(14.3 \%)$ & $3(4.3 \%)$ & NS \\
\hline Fetal distress & $9(12.9 \%)$ & $23(32.9 \%)$ & $\begin{array}{l}\mathrm{S} \\
(0.0082)\end{array}$ \\
\hline Heart disease & $2(2.9 \%)$ & $4(5.7 \%)$ & NS \\
\hline Severe anemia & $5(7.14 \%)$ & $2(2.3 \%)$ & NS \\
\hline Pre-eclampsia & $11(15.7 \%)$ & $\begin{array}{l}15 \\
(21.4 \%)\end{array}$ & NS \\
\hline Previous C.S. & $9(12.9 \%)$ & $3(4.3 \%)$ & NS \\
\hline Eclampsia & $3(4.3 \%)$ & $5(7.14 \%)$ & NS \\
\hline Maternal distress & $3(4.3 \%)$ & $3(4.3 \%)$ & NS \\
\hline $\begin{array}{l}\text { Preterm } \\
(34-37 \mathrm{wks})\end{array}$ & - & $3(4.3)$ & - \\
\hline
\end{tabular}

NS-non significant p-value ( $>0.05)$, S-significant p-value $(<0.05)$

Table 3, shows that unlike forceps delivery, vacuum delivery can be conducted in the first stage of labor with the cervical dilatation of $8 \mathrm{~cm}$ and above, but only in highly selected cases such as umbilical cord prolapse before full cervical dilatation in multigravida women.

Table 3: Cervical dilatation at the time of application of ventouse.

\begin{tabular}{|llll|}
\hline $\begin{array}{l}\text { Cervical } \\
\text { dilatation } \\
(\text { in } \mathrm{cm})\end{array}$ & $\begin{array}{l}\text { No. of } \\
\text { cases } \\
(\mathbf{n = 7 0})\end{array}$ & $\begin{array}{l}\text { Successful } \\
\text { VE }(\mathbf{n = 6 2})\end{array}$ & $\begin{array}{l}\text { Unsuccessf } \\
\text { ul VE }(\mathbf{n = 8})\end{array}$ \\
\hline 10 & 62 & 57 & 05 \\
\hline 9 & 06 & 04 & 02 \\
\hline 8 & 02 & 01 & 01 \\
\hline
\end{tabular}

Figure 1 summarizes failure rates of assisted delivery. Our study showed the failure of eight cases in ventouse group (11.4\%) and five cases in the forceps group $(7.14 \%)$. Cephalo-pelvic disproportion was the cause in majority (61.5\%). Adherence to strict guidelines for case selection and proper application of the instrument will decrease the failure rate in instrumental deliveries.

The maternal morbidity was significantly less in vacuum group as compared to forceps group $(\mathrm{p}<0.0001)$. We observed that episiotomy is given to all patients (100\%) before forceps application but only $68.6 \%$ patients required it with vacuum application. Table 4 , shows that except episiotomy extension other maternal morbidity as cervical tear, periurethral tear, vaginal tears and perineal tears were observed more frequently after forceps application.

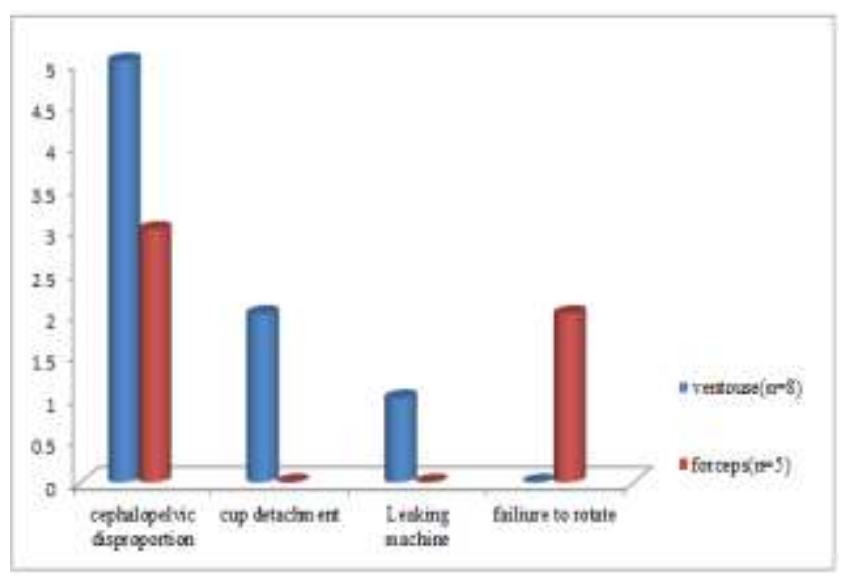

Figure 1: Reasons for failure of instruments in two study group.

Table 4: Maternal morbidity in instrumental deliveries.

\begin{tabular}{|c|c|c|c|}
\hline Morbidity & $\begin{array}{l}\text { Ventouse } \\
(\mathrm{n}=70)\end{array}$ & $\begin{array}{l}\text { Forceps } \\
(\mathbf{n}=70)\end{array}$ & P value \\
\hline Episiotomy & $48(68.6 \%)$ & $70(100 \%)$ & $\mathrm{S}(0.0001)$ \\
\hline $\begin{array}{l}\text { Episiotomy } \\
\text { extension }\end{array}$ & $11(15.7 \%)$ & $6(8.61 \%)$ & NS \\
\hline Vaginal wall tear & $1(1.4 \%)$ & $5(7.1 \%)$ & NS \\
\hline Periurethral tear & $1(1.4)$ & $8(11.4 \%)$ & $S(0.0173)$ \\
\hline $\begin{array}{l}\text { Extension to } \\
\text { fornices }\end{array}$ & - & $3(4.3 \%)$ & - \\
\hline Cervical tear & $1(1.4 \%)$ & $4(5.7 \%)$ & NS \\
\hline $\begin{array}{l}\text { First and second } \\
\text { degree perineal } \\
\text { tear }\end{array}$ & $3(4.3 \%)$ & $8(11.4 \%)$ & NS \\
\hline $\begin{array}{l}\text { Third and fourth } \\
\text { degree perineal } \\
\text { tear }\end{array}$ & $3(4.3 \%)$ & $9(12.9 \%)$ & $S(0.0171)$ \\
\hline $\begin{array}{l}\text { Post-partum } \\
\text { hemorrhage }\end{array}$ & $1(1.4 \%)$ & $5(7.1 \%)$ & NS \\
\hline $\begin{array}{l}\text { Length of } \\
\text { hospital stay }\end{array}$ & $48 \mathrm{hr}$ & $72 \mathrm{hr}$ & - \\
\hline $\begin{array}{l}\text { Blood } \\
\text { transfusion } \\
\text { needed }\end{array}$ & $1(1.4 \%)$ & $6(8.57 \%)$ & NS \\
\hline
\end{tabular}

NS-non significant p-value $(>0.05), \quad$ S-significant $p$-value $(<0.05)$

The risk of neonatal morbidity was similar between infants delivered by vacuum or forceps (Table 5). Cephalhematoma in neonate were significantly $(\mathrm{p}=0.0077)$ more common with vaccum, but instrumental 
marks and bruising were more common with forceps group ( $\mathrm{p}=0.0001)$. NICU admissions were more $(23.0 \%)$ with forceps as compared to vacuum (12.9), but this difference was statistically non-significant.

Table 5: Neonatal morbidity and mortality.

\begin{tabular}{|c|c|c|c|}
\hline Variables & $\begin{array}{l}\text { Ventouse } \\
(n=62))\end{array}$ & $\begin{array}{l}\text { Forceps } \\
(n=65)\end{array}$ & P value \\
\hline Cephalhematoma & $\begin{array}{l}11 \\
(17.8 \%)\end{array}$ & $\begin{array}{l}2 \\
(3.0 \%)\end{array}$ & $\begin{array}{l}S \\
(0.0077)\end{array}$ \\
\hline $\begin{array}{l}\text { Instrumental marks } \\
\text { and bruising }\end{array}$ & $\begin{array}{l}7 \\
(11.3 \%)\end{array}$ & $\begin{array}{l}27 \\
(41.5 \%)\end{array}$ & $\begin{array}{l}\mathrm{S} \\
(0.0001)\end{array}$ \\
\hline $\begin{array}{l}\text { Subconjunctival } \\
\text { hemorrhage }\end{array}$ & - & $\begin{array}{l}5 \\
(7.7 \%)\end{array}$ & - \\
\hline $\begin{array}{l}\text { Brachial plexus } \\
\text { injury }\end{array}$ & - & $\begin{array}{l}1 \\
(1.5 \%)\end{array}$ & - \\
\hline Convulsions & $\begin{array}{l}3 \\
(4.8 \%)\end{array}$ & $\begin{array}{l}6 \\
(9.2 \%)\end{array}$ & NS \\
\hline $\begin{array}{l}\text { Neonatal } \\
\text { hyperbilirubinemia } \\
\text { and need of } \\
\text { phototherapy }\end{array}$ & $\begin{array}{l}8 \\
(12.9 \%)\end{array}$ & $\begin{array}{l}2 \\
(3.0 \%)\end{array}$ & NS \\
\hline Feeding difficulty & $\begin{array}{l}3 \\
(4.8 \%)\end{array}$ & $\begin{array}{l}2 \\
(3.0 \%)\end{array}$ & NS \\
\hline Irritability & $1(1.6 \%)$ & $1(1.5 \%)$ & NS \\
\hline $\begin{array}{l}\text { Neonatal ICU } \\
\text { admissions }\end{array}$ & $\begin{array}{l}8 \\
(12.9 \%)\end{array}$ & $\begin{array}{l}15 \\
(23.0 \%)\end{array}$ & NS \\
\hline Perinatal mortality & - & $\begin{array}{l}2 \\
(3.0 \%)\end{array}$ & - \\
\hline
\end{tabular}

NS-non significant p-value ( $>0.05)$, S-significant p-value $(<0.05)$

\section{DISCUSSION}

The incidence of instrumental vaginal delivery in our institution in last five years was $13.8 \%$ of total births. It is still within the worldwide incidence of $2 \%-15 \% .^{12,13}$ The variation in incidence in various health institutions and the decline in practice in recent times could be attributed to variation in practice protocols, litigation, nonavailability of functional equipments and the declining skills of providers in conducting instrumental deliveries. $^{14,15}$

In the past, forceps deliveries were highly favored over vacuum extraction in North America. According to official statistics from the 1980s, the vacuum/forceps ratio in Canada and United States were both 0.03 , whereas in European countries, the ratio varied from 1.06 in Norway to13.0 in Finland. ${ }^{16}$ Currently there is tendency to rely on vacuum extraction which may be because of recent evidence of decreased maternal trauma with vacuum extraction compared to forceps deliveries in randomized trials and by a substantial improvement in the technique of vacuum extraction, especially in the material used for vacuum cups. ${ }^{17}$ In our study we also found the ratio of $1 / 6$ between forceps and vacuum application, which is in accordance with findings derived from Lurie $\mathrm{S}$ et al. ${ }^{18}$
In our study $74 \%$ of forceps delivery and $58 \%$ of ventouse deliveries were carried out in primigravida, which is in accordance with prior study done by Akhtar S. ${ }^{19}$ For vacuum delivery, common indications were to cut short the second stage of labour $(42.85 \%)$ followed by prolonged second stage of labour $(25.7 \%)$, poor maternal efforts $(14.3 \%)$ and fetal distress $(12.9 \%)$. For forceps delivery main indication was to cut short the second stage of labour (41.2\%) followed by fetal distress (32.9\%). Our study results showed that forceps are the instrument of choice in cases of fetal distress. However, different studies reported fetal distress as the commonest indication for vacuum delivery. ${ }^{19-21}$

Episiotomy was not done routinely in the ventouse group $(31.4 \%)$, especially in multigravida, but it was given in all cases of forceps deliveries. Study done by Achanna S et al also supported this association. ${ }^{22}$ We found that episiotomy extensions were more common with vacuum deliveries but this difference was statistically nonsignificant $(p=0.3007)$. Table 4 shows that maternal morbidity was significantly less in ventouse group as compared to forceps group $(\mathrm{p}=0.0172)$, which is in accordance with the results of Cochrane Database. ${ }^{23}$ It showed that vacuum extractor was associated with a lower caesarean section rate, a lower use of regional and general anesthesia, with apparently less pain at delivery, significantly less pain after $24 \mathrm{hr}$ and significantly less likely to cause serious maternal injury than forceps. It seemed that vacuum extractor could, do no harm to mother or newborn.

In a randomized controlled trial, Eason $\mathrm{E}$ showed that a decrease of 4.9 in adjusted relative risk of anal sphincter injury was noted when vacuum was used over forceps. ${ }^{24}$ Our study also reported only $1.4 \%$ patients in vacuum group had anal sphincter injury as compared to forceps group with $12.9 \%$ patients having anal sphincter injury.

Our study showed the failure rate of $7.14 \%$ with forceps and $11.4 \%$ with ventouse. Vacca A et al also reported the percentage of failure after forceps application was $7 \%$, while it is almost double (12\%) with vacuum delivery. ${ }^{25}$ Failure of vacuum and the sequential use of forceps to complete deliveries increase the maternal and neonatal morbidity.

Neonatal morbidity differ substantially among various published reports. ${ }^{22-29}$ Some authors highlight the risk of vacuum, but vacuum is generally considered as a safe alternative to forceps or with comparable outcomes concerning the neonatal morbidity. In the present study, low Apgar Score at $1 \& 5 \mathrm{~min}$, NICU admissions and duration of stay in NICU were non significantly higher after forceps application. Cephalhematoma was seen more common after vacuum application. Apart from causing neonatal jaundice, it is rarely of any significance. Instrumental marks and bruising were seen more commonly after forceps application. Both the fore mentioned complication, were dependent mainly on 
operator's skill of instrument application and case selection rather than type of instrument.

The present study was not without deficiencies, such as retrospective design and small sample of both group patients. Long term maternal and neonatal outcomes were also not studied in the study.

\section{CONCLUSION}

Instrumental vaginal delivery by experienced health care provider is associated with good obstetric outcomes with minimal risk. Our study concluded that ventouse application is associated with significantly less maternal trauma than with forceps. Neonatal outcomes were similar in both types of instrumental deliveries. The safety of the instrument is dependent mainly on operator's skills and right judgment regarding case selection. Improved training of residents in instrumental delivery may help to reduce the unwarranted and raised caesarean section rates.

\section{Funding: No funding sources}

Conflict of interest: None declared

Ethical approval: The study was approved by the Institutional Ethics Committee

\section{REFERENCES}

1. Anonymous. Vacuum versus forceps. (Editorial). Lancet. 1984;1:144.

2. Meniru GI. An analysis of recent trends in vacuum extraction and forceps delivery in the United Kingdom. BJOG: An Intern J Obstetr Gynaecol. 1996;103(2):168-70.

3. Learman LA. Regional differences in operative obstetrics: a look to the South. Obstetrics \& Gynecology. 1998;92(4 Part 1):514-9.

4. Hillier CE, Johanson RB. Worldwide survey of assisted vaginal delivery. Intern J Gynecol Obstetr. 1994;47(2):109-14.

5. Johanson RB, Rice C, Doyle M, Arthur J, Anyanwu $\mathrm{L}$, Ibrahim $\mathrm{J}$, et al. A randomised prospective study comparing the new vacuum extractor policy with forceps delivery. Intern $\mathbf{J}$ Obstetr Gynaecol. 1993;100(6):524-30.

6. Caughey AB, Sandberg PL, Zlatnik MG, Thiet MP, Parer JT, Laros Jr RK. Forceps compared with vacuum: rates of neonatal and maternal morbidity. Obstetr Gynecol. 2006;107(3):740.

7. Bofill JA, Rust OA, Schorr SJ, Brown RC, Martin RW, Martin JN, et al. A randomized prospective trial of the obstetric forceps versus the M-cup vacuum extractor. Am J Obstetr Gynecol. 1996;175(5):132530.

8. Johnson JH, Figueroa R, Garry D, Elimian A, Maulik D. Immediate maternal and neonatal effects of forceps and vacuum-assisted deliveries. Obstetr Gynecol. 2004;103(3):513-8.
9. Vacca A, Grant A, Wyatt G, Chalmers I. Portsmouth operative delivery trial: a comparison vacuum extraction and forceps delivery. Intern $\mathrm{J}$ Obstetr Gynaecol. 1983;90(12):1107-12.

10. Towner D, Castro MA, Eby-Wilkens E, Gilbert WM. Effect of mode of delivery in nulliparous women on neonatal intracranial injury. New England journal of medicine. 1999;341(23):1709-14.

11. Wen SW, Liu S, Kramer MS, Marcoux S, Ohlsson A, Sauvé R, et al. Comparison of maternal and infant outcomes between vacuum extraction and forceps deliveries. American journal of epidemiology. 2001;153(2):103-7.

12. Pam IC, Otubu JA. Instrumental delivery. In: Agboola A, editor. Textbook of Obstetrics and Gynaecology for Medical Students. 2nd ed. Ibadan: Heinemann Educational Books Nig. Plc; 2006:489494.

13. Hook CD, Damos JR. Vacuum-assisted vaginal delivery. Am Family Physician. 2008;78(8): 953-60.

14. Lawani LO, Anozie OB, Ezeonu PO, Iyoke CA. Comparison of outcomes between operative vaginal deliveries and spontaneous vaginal deliveries in southeast Nigeria. Intern $\mathbf{J}$ Gynecol Obstetr. 2014;125(3):206-9.

15. Arias F, Daftary SN, Bhide AG. Abnormal labour and delivery. Operative vaginal delivery. IN:Arias F, Daftary SN, Bhide AG, eds. Practical guide to high risk pregnancy and delivery,a south-asian perspective. 3rd ed. India: Elsievier Health Sciences; 2008:86-396.

16. Chalmers I, Enkin M, Keirse MJ. Effective care in pregnancy and childbirth: Pregnancy. Oxford University Press, USA; 1989.

17. Okunwobi-Smith Y, Cooke I, MacKenzie IZ. Decision to delivery intervals for assisted vaginal vertex delivery. Intern $\mathbf{J}$ Obstetr Gynaecol. 2000;107(4):467-71.

18. Lurie S, Glezerman M, Sadan O. Maternal and neonatal effects of forceps versus vacuum operative vaginal delivery. Intern $\mathbf{J}$ Gynecol Obstetr. 2005;89(3):293-4.

19. Akhtar S. Comparison of maternal and infant outcome between vacuum extraction and forceps deliveries. Pakistan Armed Force Med J. 2006;2(1):25-31.

20. Nkwabong E, Nana PN, Mbu R, Takang W, Ekono MR, Kouam L. Indications and maternofetal outcome of instrumental deliveries at the University Teaching Hospital of Yaounde, Cameroon. Tropical doctor. 2011;41(1):5-7.

21. Singh A, Rathore P. A comparative study of fetomaternal outcome in instrumental vaginal delivery. The Journal of Obstetrics and Gynecology of India. 2011;61(6):663-6.

22. Achanna S, Monga D. Outcome of forceps delivery versus vacuum extraction-a review of 200 cases. Parity. 1994;3(1.4):3-4. 
23. Johanson RB, Menon BK. Vacuum extraction versus forceps for assisted vaginal delivery. Cochrane Database Syst Rev. 2000;2:CD000224.

24. Eason E, Labrecque M, Marcoux S, Mondor M.. Anal incontinence after childbirth. CMAJ: Canadian Med Assoc J. 2002;166(3):326-30.

25. Johanson R, Menon V. Soft versus rigid vacuum extractor cups for assisted vaginal delivery. The Cochrane Library. 2000.

26. Demissie K, Rhoads GG, Smulian JC, Balasubramanian BA, Gandhi K, Joseph KS, et al. Operative vaginal delivery and neonatal and infant adverse outcomes: population based retrospective analysis. BMJ. 2004;329(7456):24.

27. Gardella C, Taylor M, Benedetti T, Hitti J, Critchlow C. The effect of sequential use of vacuum and forceps for assisted vaginal delivery on neonatal and maternal outcomes. Am Journal of Obstetr Gynecol. 2001;185(4):896-902.
28. Lamba A, Kaur R, Muzafar Z. An observational study to evaluate the maternal and neonatal outcome of forceps delivery in a tertiary care government hospital of a cosmopolitan city of India. Age (years). 2016;20(17):24.

29. Prameela RC, Prajwal S. Assisted vaginal delivery, Forceps, Ventouse. Outcome of instrumental vaginal deliveries in referred cases. Journal of evolution of medical and dental sciences 2015;4(19):3275-80.

Cite this article as: Chaudhari $\mathrm{P}$, Bansal N, Gupta V, Tandon A, Chaudhry A. A comparative study of feto-maternal outcome in instrumental vaginal delivery at tertiary health level hospital in Uttarakhand state. Int J Reprod Contracept Obstet Gynecol 2016;5:3294-9. 